Conclusion: New-onset gout was independently associated with a $51 \%$ increased risk of return to dialysis $>12$ months after primary KT compared to a control cohort without gout. To our knowledge, this is the first observation of this outcome in an appropriately controlled cohort study of KT recipients with gout. Results from this analysis may have important implications for the monitoring and management of new-onset gout in the kidney transplant population.

References:

[1] Mandell BF. Cleve Clin J Med 2008;75(Suppl 5):S5-8.

[2] Forbess LJ, Fields TR. Sem Arthritis Rheum 2012;42:146-54.

[3] Gibson T. Curr Opin Rheumatol 2012;24:127-31.

[4] Zhang L, et al. Nephrol Dial Transplant 2012;27:1836-9.

[5] Clive DM. J Am Soc Nephrol 2000;11:974-9.

[6] Kalantar E, et al. Transplant Proc 2011;43:584-5.

[7] Lin HY, et al. N Engl J Med 1989;321:287-92.

[8] Ben Hmida M, et al. Transplant Proc 1995;27:2722-4.

[9] Kanbay M, et al. Transplant Proc 2005;37:3119-20.

[10] Baroletti S, Bencivenga GA. Prog Transplant 2004;14:143-7.

[11] Kim ED, et al. Am J Transplant 2015;15:482-8.

[12] Kim DG, et al. PloS One 2018;13:e0209156.

Disclosure of Interests: : Justin Li: None declared, David Yin: None declared, Zheng Wang: None declared, Mark Brigham: None declared, Brian LaMoreaux Shareholder of: Horizon Therapeutics, Employee of: Horizon Therapeutics, Jeffrey Kent Shareholder of: Horizon Therapeutics, Employee of: Horizon Therapeutics, Megan Francis-Sedlak Shareholder of: Horizon Therapeutics, Employee of: Horizon Therapeutics, Richard Johnson Shareholder of: Colorado Research Partners LLC, XORTX Therapeutics, Consultant of: Horizon Therapeutics, Eli Lilly, Speakers bureau: Horizon Therapeutics, Nandini Hadker: None declared, Kevin Francis: None declared, Herman Sanchez: None declared, Gavin Miyasato: None declared

DOI: 10.1136/annrheumdis-2020-eular.2060

\section{THU0409 A RANDOMIZED, PHASE 2 STUDY EVALUATING THE EFFICACY AND SAFETY OF ANAKINRA IN DIFFICULT- TO-TREAT ACUTE GOUTY ARTHRITIS: THE ANAGO STUDY}

K. Saag ${ }^{1}$, A. So ${ }^{2}$, P. Khanna ${ }^{3}$, R. Keenan ${ }^{4}$, S. Ohlman ${ }^{5}$, T. Kullenberg ${ }^{5}$, L. Osterling Koskinen ${ }^{5}$, M. H. Pillinger ${ }^{6}$, R. Terkeltaub ${ }^{7} .{ }^{1}$ Uni Alabama, Birmingham, United States of America; ${ }^{2}$ Uni Lausanne, Lausanne, Switzerland; ${ }^{3}$ Uni Michigan, Ann Arbor, United States of America; ${ }^{4}$ Duke Uni School Med, Durham, United States of America; ${ }^{5}$ Sobi, Stockholm, Sweden; ${ }^{6}$ New York Uni School Med, New York, United States of America; ${ }^{7}$ Uni California San Diego, La Jolla, United States of America

Background: In gout, urate crystals deposited in and around joints trigger episodes of acute arthritis, mediated by the proinflammatory cytokine IL-1 $\beta$. In uncontrolled studies, the IL-1 receptor antagonist anakinra appears effective in reducing pain and signs of acute flares in patients with difficult-to-treat gout. However, confirmatory, adequately-powered, prospective trials are lacking. The 'anaGO-study' (anakinra in gout) was a multi-center, randomized, double-blind, double-dummy, phase 2 study investigating the efficacy and safety of anakinra in acute gout (NCT03002974).

Objectives: The primary objective was to evaluate the efficacy of two regimens of anakinra ( 100 or $200 \mathrm{mg}$ daily s.c. injections for 5 days) compared to triamcinolone (single i.m. injection $40 \mathrm{mg}$ ) with respect to patient-assessed pain intensity. The primary endpoint was change in pain intensity from baseline to 24-72 hours (average of 24, 48 and 72 hours) in the most affected joint measured on a visual analogue scale (0-100 VAS). Secondary outcomes included: time to onset of effect, time to response, time to pain resolution, time to rescue medication use, patient's and physician's assessments of global response, clinical signs, inflammatory biomarkers and safety.

Methods: Patients were recruited who had acute gout based on ACR/EULAR 2015 gout classification criteria, and were unsuitable for anti-inflammatory therapy with NSAIDs and colchicine due to contraindication, intolerance or inefficacy. Patients were randomized to each group in a $1: 1: 1$ ratio and stratified by urate-lowering therapy use (yes $/ \mathrm{no}$ ) and BMI ( $<30.0$ or $\left.\geq 30.0 \mathrm{~kg} / \mathrm{m}^{2}\right)$.

Results: 165 patients were randomized; 110 to anakinra ( 56 to $100 \mathrm{mg} /$ day, 54 to $200 \mathrm{mg} / \mathrm{day}$ ) and 55 to triamcinolone; 108 and 53 were included in the primary analysis, respectively. The median (range) age was $55(25-83)$ years, $87 \%$ were male, mean disease duration was 8.7 years and mean number of selfreported flares during the past year was 4.5 . The pain intensity, from baseline to 24-72 hours, decreased in both treatment groups; mean $(95 \% \mathrm{Cl})$ change was $-39.4(-46.8,-32.0)$ for triamcinolone and $-41.2(-46.3,-36.2)$ for anakinra. The $100 \mathrm{mg}$ and $200 \mathrm{mg}$ doses of anakinra were comparably effective in decreasing pain (100 mg/day: $-41.8[-48.9,-34.8]$ and $200 \mathrm{mg} /$ day: $-40.7[-47.9,-33.4])$.
Mean $(95 \% \mathrm{Cl})$ difference in pain reduction between anakinra and triamcinolone treatment groups was $-1.8(-10.8,7.1)$ ( $p$-value $=0.688$ for primary endpoint) The majority of secondary efficacy endpoints were numerically in favor of anakinra, and in most instances also statistically significant, in comparison to triamcinolone, e.g. physician's assessment of clinical signs at 72 hours and patient's and physician's assessment of global response at Day 8. No unexpected safety findings were identified in any of the treatment groups.

Conclusion: Anakinra and triamcinolone reduced patient-assessed gout flare pain to similar degrees in patients for whom conventional therapy was ineffective or contraindicated. Both doses of anakinra showed comparable efficacy in pain reduction. The majority of secondary efficacy endpoints favored anakinra. Anakinra was shown to be an additional option for use during acute gout flares.

\section{Patient-assessed pain intensity (VAS) in index joint at each time} point after treatment

(mixed model repeated measures analysis, intention-to-treat population)

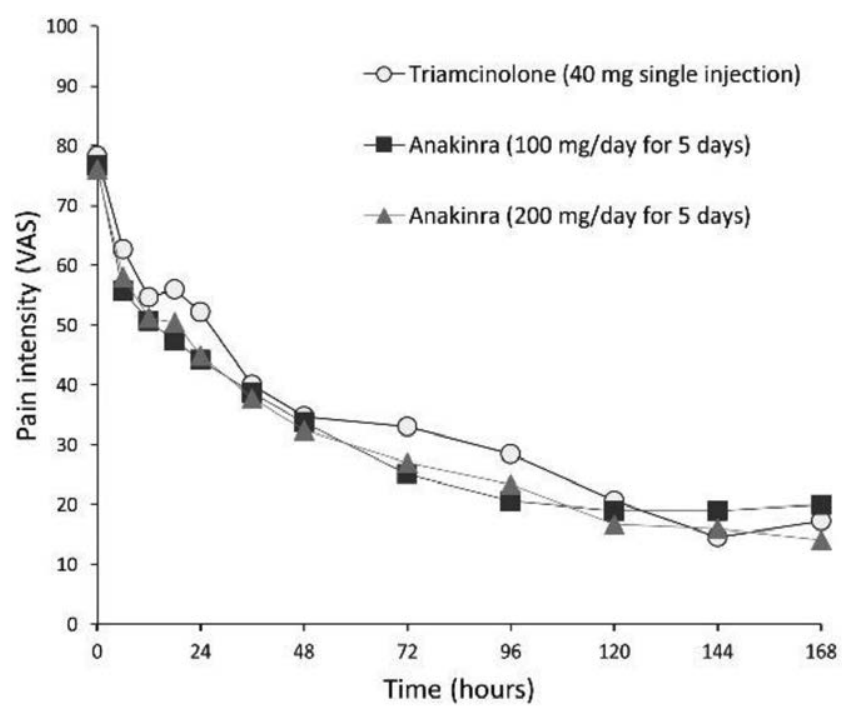

Disclosure of Interests: : Kenneth Saag Grant/research support from: Horizon Sobi, Shanton, Grant/research support from: Horizon Pharma, Sobi, Shanton, Consultant of: Horizon and Sobi, Consultant of: Horizon Pharma, Amgen, Radius, LG-Pharma, Takeda, Sobi, Atom, Arthrosi, Alexander So Consultant of: Sobi, Grünenthal, Puja Khanna Grant/research support from: Dyve, Selecta, Sobi, Consultant of: Sobi, Horizon, Robert Keenan Consultant of: Sobi, Selecta, Horizon, Sven Ohlman Shareholder of: Sobi, Employee of: Former employee of Sobi, Torbjörn Kullenberg Shareholder of: Sobi, Employee of: Former employee of Sobi, Lisa Osterling Koskinen Shareholder of: Sobi, Employee of: Sobi, Michael H. Pillinger Grant/research support from: Horizon, Hikma, Consultant of: Sobi, Horizon, Robert Terkeltaub Consultant of: Sobi, Selecta, Horizon, Astra-Zeneca DOI: 10.1136/annrheumdis-2020-eular.3766

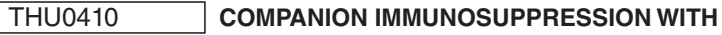 AZATHIOPRINE INCREASES THE FREQUENCY OF PERSISTENT RESPONSIVENESS TO PEGLOTICASE IN PATIENTS WITH CHRONIC REFRACTORY GOUT}

H. Rainey ${ }^{1}$, H. S. B. Baraf ${ }^{2}$, A. Yeo ${ }^{1}$, P. Lipsky ${ }^{1} .{ }^{1}$ AMPEL BioSolutions, Charlottesville, United States of America; ${ }^{2}$ Center for Rheumatology and Bone Research, Wheaton, United States of America

Background: Pegloticase is a mammalian recombinant uricase coupled to monomethoxy polyethylene glycol that is approved in the US for treatment of patients with chronic refractory gout and causes profound reductions in serum urate. However, treatment with pegloticase is limited by the induction of anti-drug antibodies and loss of responsiveness in nearly half of treated patients.

Objectives: The goal of this study was to determine whether co-therapy with azathioprine (AZA) would increase the frequency of chronic refractory gout patients who had persistent urate lowering from pegloticase therapy.

Methods: This open label multicenter study enrolled subjects with chronic gout who failed to lower serum urate to $<6 \mathrm{mg} / \mathrm{dL}$ despite medically indicated doses of urate lowering therapy (NCT02598596). Patients were screened for adequate levels of the AZA metabolizing enzyme thiopurine methyl transferase and then started on daily oral AZA $1.25 \mathrm{mg} / \mathrm{kg}$ for 1 week and then $2.5 \mathrm{mg} / \mathrm{kg}$ for 
the remainder of the trial. Blood levels of AZA metabolites 6-thioguanine and 6-methylmercaptopurine were measured biweekly. After receiving 2 weeks of AZA, patients were started on pegloticase $(8 \mathrm{mg} I V)$ and were treated biweekly for 24 weeks. The primary endpoint was the persistent lowering of serum urate to $<6 \mathrm{mg} / \mathrm{dL}$ at the last three consecutive study visits. Patients who had an increase in serum urate to $>6 \mathrm{mg} / \mathrm{dL}$ while on therapy did not receive additional pegloticase. All patients received infusion prophylaxis with hydrocortisone as well as gout flare prophylaxis.

Results: To date, 12 patients have been enrolled. All patients were male, $75 \%$ white and $25 \%$ African American. Mean age was $62.4 \pm 14.7$ years, the mean BMI was $31.1 \pm 4.5$ and the mean duration of gout was $13.8 \pm 9.2$ years. At baseline, all patients had visible tophi; $58.3 \%$ suffered from gout flares; $81.8 \%$ had hypertension; $45.5 \%$ had dyslipidemia and $9.0 \%$ had coronary artery disease. Of the 12 patients, 6 have completed the full course of treatment with persistent urate lowering and 2 remain on treatment also with persistent urate lowering (figure). 2 patients lost the urate lowering effect, both after 2 doses of pegloticase, and did not receive additional therapy. 1 patient experienced an infusion reaction during the first dose (1 infusion reaction in 90 infusions [1.1\%] in the entire trial to date) and 1 subject had subjective symptoms of AZA intolerance with no laboratory abnormalities; these subjects discontinued the study and were not evaluable for the endpoint. No adverse events related to AZA were reported and gout flares were noted in 6 subjects (mean 1.5 flares/patient with flares).

Conclusion: AZA can be used safely in subjects with chronic refractory gout and appears to increase the frequency of subjects experiencing long term lowering of serum urate.

References:

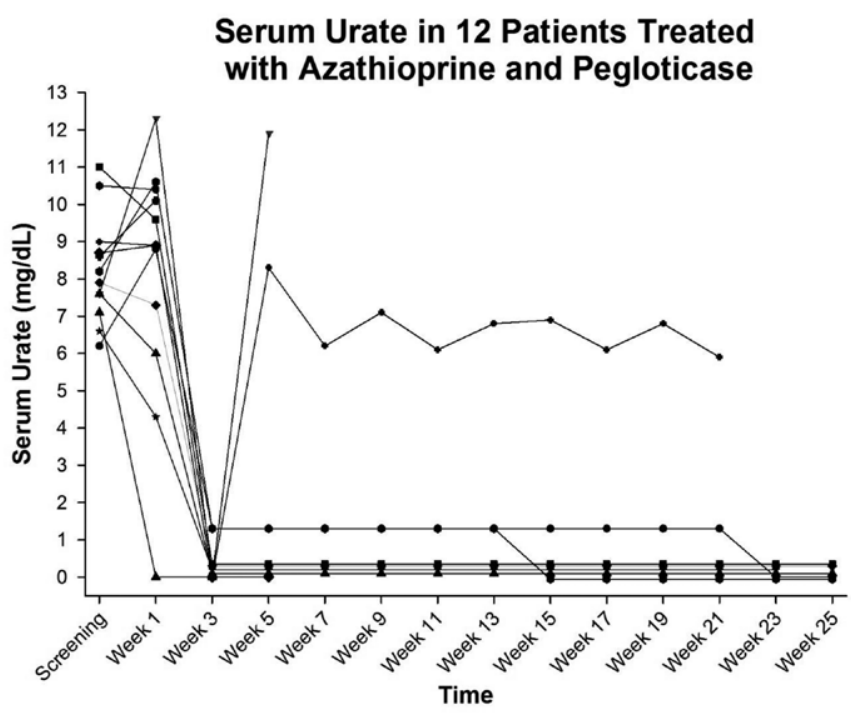

Disclosure of Interests: : Hope Rainey: None declared, Herbert S.B. Baraf Grant/research support from: Horizon; Gilead Sciences, Inc.; Pfizer; Janssen; AbbVie, Consultant of: Horizon; Gilead Sciences, Inc.; Merck; AbbVie, Speakers bureau: Horizon, Anthony Yeo Employee of: Horizon, Peter Lipsky Consultant of: Horizon Therapeutics

DOI: 10.1136/annrheumdis-2020-eular.4642

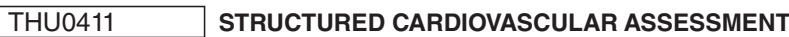 INCLUDING CAROTID ULTRASOUND IN GOUT: ANALYSIS OF SUBSEQUENT EVENTS INTHE FOLLOW UP}

M. Monzó ${ }^{1}$, N. Quilis Marti ${ }^{2}$, L. Ranieri' ${ }^{2}$ A. San-Martín ${ }^{3}$, M. Andrés $s^{1,4}$

${ }^{1}$ Universidad Miguel Hernandez de Elche, Departamento de Medicina Clínica, Alicante, Spain; ${ }^{2}$ Hospital Universitario del Vinalopó, Servicio de Reumatología, Elche, Spain; ${ }^{3}$ Clínica HLA Vistahermosa, Unidad de Reumatolog ía, Alicante, Spain; ${ }^{4}$ Hospital General Universitario de Alicante-ISABIAL, Sección de Reumatología, Alicante, Spain

Background: Gout is an independent cardiovascular (CV) risk factor. This excess of morbidity and mortality requires optimal management, especially in high-risk individuals. So, the inclusion of subclinical atherosclerosis screening by carotid ultrasound in the initial evaluation may help to accurately stratify the CV risk. However, longitudinal outcomes using this technique are not available in gout.
Objectives: To analyze the new CV events occurred in patients with gout after structured CV assessment incorporating carotid ultrasound.

Methods: Retrospective analysis of an inception cohort of new patients with crystal-proven gout. At baseline, a structured CV assessment was performed considering age, gender, traditional risk factors, CV and renal disease, laboratory data, SCORE and Framingham risk tools and carotid ultrasound; according to 2013 ESC guidelines, CV risk was stratified as low, moderate, high or very high The cohort includes 356 patients, mean aged 64 years (SD 14.0) mostly males $(86.0 \%), 21.8 \%$ with tophaceous gout and mean serum urate at diagnosis of $8.2 \mathrm{mg} / \mathrm{dL}$ (SD 1.8). The CV risk stratification was: low in 20 (5.6\%), moderate in $47(13.2 \%)$, high in $34(9.6 \%)$, and very high risk in $242(68.0 \%)$. Major CV events (coronary disease (CD), heart failure (HF), stroke, peripheral artery disease (PAD) and CV death) were recorded during the follow-up by electronic case reports review. A binary composite endpoint of "new major CV event" was used. The incidence after inclusion in the cohort was estimated. To evaluate potential baseline predictors (clinical and gout-related) of $\mathrm{CV}$ events, a Cox regression model was built.

Results: Mean follow-up in the cohort was 41.5 months (SD 16.8). Forty new major CV events have been identified (incidence 3.25\%/patient-year), distributed as follows: HF $1.46(n=18), C V$ death $0.65(n=8)$, CD $0.49(n=6)$, stroke 0.33 $(n=4)$, and PAD $0.33 \% /$ patient-year $(n=4)$. Per risk stratification, the incidence of a new event was $0.16 \%$ patient-year in the high-risk group and $3.01 \%$ /patientyear in the very high-risk, while no events occurred in low and moderate groups. The table shows the univariate and multivariate analysis of baseline variables. An independent association and a trend towards significance were noted for age and to be classified at a very high $\mathrm{CV}$ risk at baseline, respectively.

\begin{tabular}{lcccc}
\hline & \multicolumn{2}{c}{ Univariate regression } & \multicolumn{2}{c}{ Multivariate regression } \\
\hline & $\mathrm{HR}(95 \% \mathrm{Cl})$ & \multicolumn{1}{c}{$P$} & $\mathrm{HR}(95 \% \mathrm{Cl})$ & $P$ \\
\hline Age & $1.07(1.04-1.11)$ & $<0.001$ & $1.04(1.00-1.08)$ & 0.031 \\
Female gender & $3.27(1.68-6.33)$ & $<0.001$ & $1.24(0.55-2.81)$ & 0.605 \\
Body mass index & $1.00(0.94-1.06)$ & 0.863 & - & - \\
Glomerular filtration rate & $0.98(0.97-0.99)$ & $<0.001$ & $1.00(0.99-1.01)$ & 0.766 \\
Very high CV risk at baseline & $9.54(2.30-39.64)$ & 0.002 & $4.11(0.89-19.02)$ & 0.070 \\
Serum urate at diagnosis & $1.19(1.00-1.42)$ & 0.052 & $1.12(0.94-1.33)$ & 0.227 \\
ULT at diagnosis & $0.81(0.29-2.27)$ & 0.688 & - & - \\
Tophi & $1.33(0.66-2.66)$ & 0.422 & - & - \\
Years since first flare & $1.00(0.97-1.03)$ & 0.772 & - & - \\
Number of flares suffered & $0.99(0.97-1.00)$ & 0.255 & - & - \\
Number of involved joints & $1.00(0.89-1.12)$ & 0.976 & - & - \\
Joint pattern at presentation & & & & - \\
-Monoarticular & $1.00($ ref $)$ & - & $1.00($ ref $)$ & - \\
-Oligoarticular & $1.86(0.91-3.80)$ & 0.089 & $1.35(0.65-2.82)$ & 0.421 \\
-Polyarticular & $2.75(1.05-7.22)$ & 0.039 & $1.34(0.48-3.76)$ & 0.579 \\
\end{tabular}

HR: Hazard ratio; $95 \% \mathrm{Cl}$ : 95\% confidence interval.

Conclusion: First longitudinal study assessing the use of subclinical atherosclerosis screening as part of CV risk assessment in new patients with gout. Those classified at the very high-risk group presented the majority of events, being HF the most frequent. Age, and likely to be classified as very high risk, independently predicted a new CV event during follow-up, data that may be of interest in terms of management of the patient with gout at the time of diagnosis.

Disclosure of Interests: : Mar Monzó: None declared, Neus Quilis Marti: None declared, Laura Ranieri: None declared, Alejandro San-Martín: None declared, Mariano Andrés Grant/research support from: Grünenthal, Consultant of: Grünenthal, Menarini, Speakers bureau: Grünenthal, Horizon DOI: 10.1136/annrheumdis-2020-eular.4965

\section{THU0412 EFFECT OF METFORMIN ON CLINICAL GOUT OUTCOMES IN GOUT PATIENTS WITH DIABETES MELLITUS}

F. Veenstra ${ }^{1}$, L. M. Verhoef ${ }^{1}$, M. Opdam ${ }^{1}$, A. Den Broeder ${ }^{1,2}$, W. Y. Kwok ${ }^{3}$, I. Meek $^{2}$, F. Van den Hoogen ${ }^{1,2}$, M. Flendrie ${ }^{1}$, N. Van Herwaarden ${ }^{1,2}$. ${ }^{1}$ Sint Maartenskliniek, Rheumatology, Ubbergen, Netherlands; ${ }^{2}$ Radboud University Medical Center, Rheumatology, Nijmegen, Netherlands; ${ }^{3}$ Rijnstate, Rheumatology, Arnhem, Netherlands

Background: Gout and diabetes mellitus type 2 (DM) are frequently co-existing Metformin is the first choice of treatment for patients with DM type 2, and might based on previous studies - have beneficial clinical effects on gout through a putative anti-inflammatory as well as serum uric acid (SUA) lowering effect. ${ }^{1,2,3}$ Objectives: To investigate the anti-inflammatory and SUA lowering effect of metformin in patients with gout starting uric acid lowering treatment (ULT). 